This item was submitted to Loughborough's Research Repository by the author.

Items in Figshare are protected by copyright, with all rights reserved, unless otherwise indicated.

\title{
A new experimental study of influence of fabric permeability, clothing sizes, openings and wind on regional ventilation rates
}

PLEASE CITE THE PUBLISHED VERSION

http://dx.doi.org/10.1007/s12221-013-1906-5

\section{PUBLISHER}

(C) Springer and the Korean Fiber Society

\section{VERSION}

AM (Accepted Manuscript)

\section{LICENCE}

CC BY-NC-ND 4.0

\section{REPOSITORY RECORD}

Ke, Ying, Jun Li, Xiaohui Li, and George Havenith. 2019. "A New Experimental Study of Influence of Fabric Permeability, Clothing Sizes, Openings and Wind on Regional Ventilation Rates". figshare.

https://hdl.handle.net/2134/13922. 
This item was submitted to Loughborough's Institutional Repository (https://dspace.lboro.ac.uk/) by the author and is made available under the following Creative Commons Licence conditions.

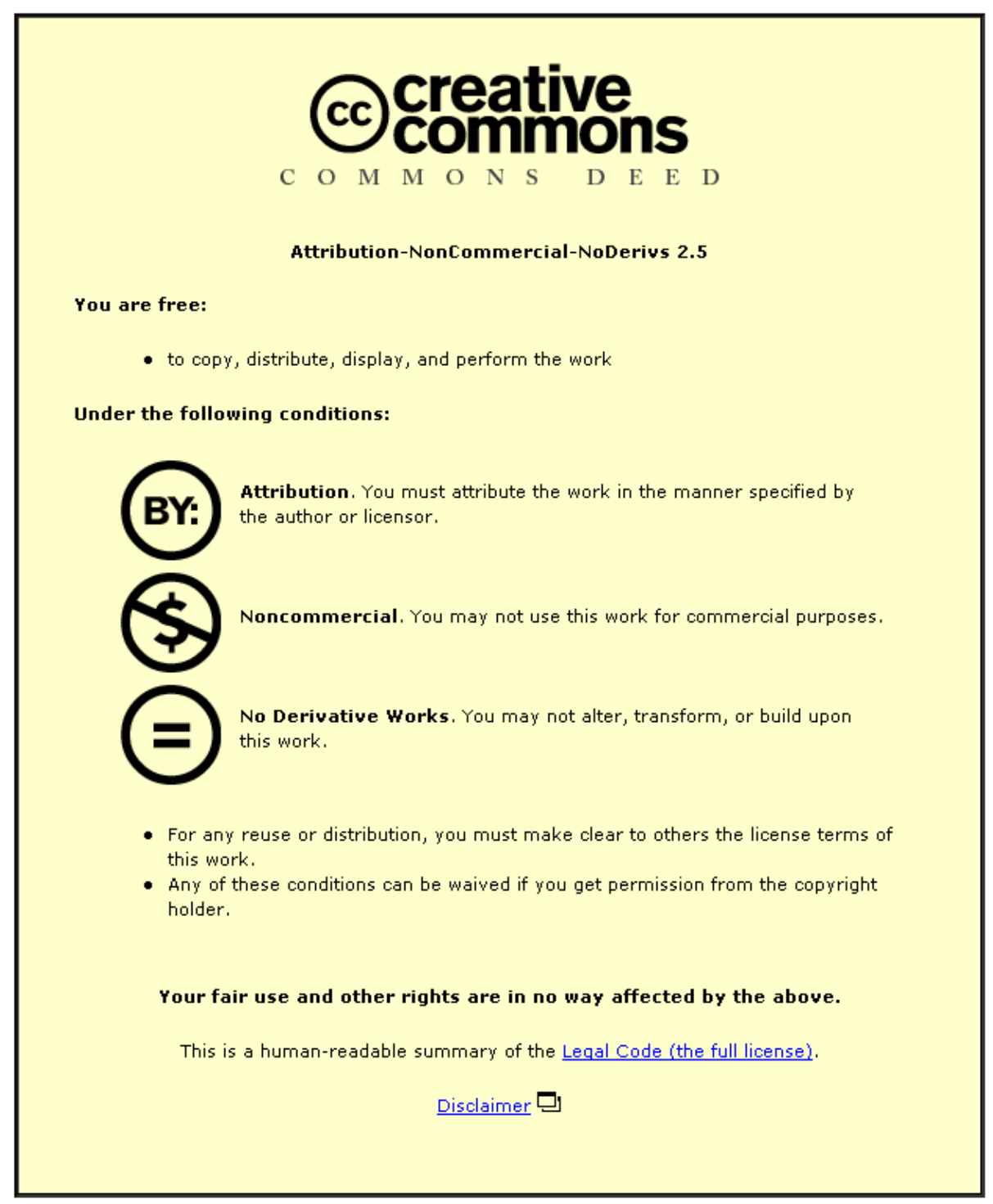

For the full text of this licence, please go to: http://creativecommons.org/licenses/by-nc-nd/2.5/ 
- Ke Y, Li J, Li X, Havenith G

Fibers and Polymers 14(11):1906-1911 2013 DOI

http://dx.doi.org/10.1007/s12221-013-1906-5

\title{
A New Experimental Study of Influence of Fabric Permeability, Clothing sizes, Openings and Wind on Regional Ventilation \\ Rates
}

\author{
Ying Ke ${ }^{1,2,3}$, George Havenith ${ }^{4}$ Jun $\mathrm{Li}^{1,2,3 *}$, Xiaohui $\mathrm{Li}^{1,2,3}$ \\ ${ }^{1}$ Fashion Institute, Donghua University, Shanghai 200051, China \\ ${ }^{2}$ Protective Clothing Research Center, Donghua University, Shanghai 200051, China \\ ${ }^{3}$ Key Laboratory of Clothing Design \& Technology, Ministry of Education, Shanghai 200051, China \\ ${ }^{4}$ Environmental Ergonomics Research Center, Loughborough University, Loughborough LE113TU, UK
}

\begin{abstract}
In this study, a local ventilation rates (VR) measuring system based on stead-state method was developed. This system can measure the local VR of the right arm, the left arm, the chest and the back locations of the upper body garment simultaneously. The whole clothing VR can also be computed. To study the influence of fabric permeability, clothing sizes, hem opening, and wind on local VR of the right arm, the chest and the back of the working garments, 9 jackets with different sizes and fabric permeability (permeable, semi-permeable and impermeable) were made. The results showed that the local VR for each garment location were significantly different. The chest had the largest local VR. Clothing ventilation rates were not liner with garment sizes. Closing garment bottom decreased more air exchange for chest and back comparatively. Wind increased both local and whole VR significantly. But the impacts were different according to different locations.
\end{abstract}


Keywords: Fabric permeability, Clothing sizes, Openings, Wind, Local ventilation rates, Whole ventilation rates.

Introduction

*Corresponding author: lijun@dhu.edu.cn

ing systems have been built recently based on the two basic methods[7-11].

Working people sweat easily on period. Many studies focused on the regional body sweat mapping[7, 10, 12-16]. It has been proved that the

Clothing microclimate ventilation is an effective way to lose heat, especially for garments that have special functions[1].It determines human thermal comfort both in hot and cold environments[2-4]. Two techniques-Crockford's method (CR) and Lotens \& Havenith's method (LH) based on the tracer gas dilution method have been developed to measure whole garment ventilation[1, 5, 6]. Havenith et al. compared the two methods on reproducibility, validity, sensitivity and applicability of them for the determination of microclimate ventilation and vapor resistance and found that both methods worked well[4]. But the CR method needs to measure the microclimate volume, which is complicated and error prone. Some other ventilation measur- sweat rates at different locations were different[7, 10, 12-16]. In addition, the local microclimate(air gap thicknesses and microclimate volumes) of each garment location were also different. Clothing microclimate is one of the main factors that affects ventilation rates[17]. Therefore the local ventilation rates are also different at different garment locations. Thus it is of high importance to measure clothing local ventilation.

Two local ventilation measuring systems have been developed recently. One was built by Satsumoto and Havenith (SH)[11]. And the other was built by Ueda et al. (UI)[10]. SH used steady state method to evaluate four parts local ventilation. But the method needed to control the inlet and outlet flow rate precisely the same. In 
addition, SH system can only measure one part

ventilation once, which wasted trace gas and

Experimental

extends testing time. UI used unsteady state

method to evaluate chest, back and upper arm

ventilation separately. And the clothing micro-

Fabrics and garments

climate was approximated using a cylinder

method[18].

In this study, a local ventilation measuring

system based on LH method was developed.

This system can measure the local ventilation

rates of four garment locations at the same time.

Using this system, we studied the influence of

the fabric permeability, clothing sizes, openings,

and wind on the local ventilation rates (VR). In

addition, this system can also measure clothing

whole ventilation indirectly. Whole ventilation

of the nine working jackets were also computed in Tab.2 and Fig.1.

and compared.

in permeability, named as impermeable (IM),

semi-permeable (SM) and permeable (PM)

were chosen. Tab.1 shows the basic properties of the fabrics. For impermeable fabric, this is semi-permeable fabric laminated with an impermeable thin coating. 9 working jackets, identical in design but different in size: S1, S2 and S3, were made with these fabrics separately. Details of the 9 experimental jackets are shown

Tab. 1 Basic parameters of the fabric samples

\begin{tabular}{|c|c|c|c|c|c|c|c|c|c|c|}
\hline Sam- & Struc- & Warp & Weft & Thick- & & \multicolumn{2}{|c|}{ Bending rigidity } & Thermal & Vapor & Air per- \\
\hline ples & ture & den- & den- & ness & & Warp & Weft & Re- & re- & meability \\
\hline
\end{tabular}




\begin{tabular}{|c|c|c|c|c|c|c|c|c|c|c|}
\hline & & sity & sity & & & & & sistance & sistance & \\
\hline & & /inch & /inch & $\mathrm{mm}$ & $\mathrm{g} / \mathrm{m}^{2}$ & \multicolumn{2}{|c|}{$\mathrm{gf} \cdot \mathrm{cm}^{2} / \mathrm{cm}$} & ${ }^{\circ} \mathrm{C} \cdot \mathrm{m}^{2} /$ & $\mathrm{Pa} \cdot \mathrm{m}^{2} /$ & $\mathrm{mm} / \mathrm{s}$ \\
\hline IM & Twill & 101 & 56 & 0.48 & 248.90 & 0.0983 & 0.1433 & 0.0071 & -- & 0.00 \\
\hline SM & Twill & 101 & 56 & 0.48 & 233.14 & 0.0453 & 0.0667 & 0.0096 & 3.15 & 59.00 \\
\hline PM & Twill & 78 & 55 & 0.48 & 186.30 & 0.0503 & 0.0155 & 0.0162 & 2.80 & 135.18 \\
\hline
\end{tabular}

Tab. 2 Basic measurements of the experimental garments

\begin{tabular}{ccccccccc}
\hline & Bust & Waist & Hip & Neck line & Cuff around & Bottom around & Jacket length & Sleeve length \\
\cline { 2 - 8 } Garment size & $\mathrm{cm}$ & $\mathrm{cm}$ & $\mathrm{cm}$ & $\mathrm{cm}$ & $\mathrm{cm}$ & $\mathrm{cm}$ & $\mathrm{cm}$ & $\mathrm{cm}$ \\
\hline S1 & 120 & 110 & 116 & 38 & 14 & 98 & 65 & 58 \\
S2 & 124 & 114 & 120 & 38.5 & 14.5 & 102 & 66 & 59 \\
S3 & 128 & 118 & 124 & 39 & 15 & 106 & 67 & 60 \\
\hline
\end{tabular}

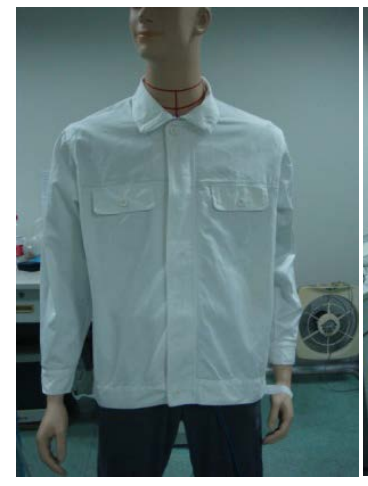

(a)

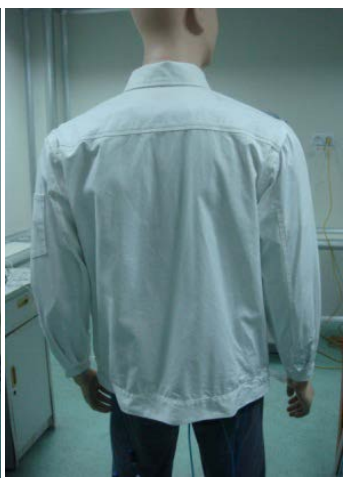

(b)

\section{Local ventilation measuring system}

We divided the upper body garment into 4 parts: the chest, the back, the right arm and the left arm. The upper body and the experimental garments have approximately vertical symmetry.

Fig. 1 Photograph of the experimental jacket and the shop manikin. (a) Front view; (b) Back view 
rates of the right arm equals the left arm's.

A steady state tracer gas method was used for measuring microclimate ventilation rates. Fig.2 shows the schematic diagram of the ventilation system for one part. Each system is separate from others. And Fig. 3 presents the photograph of the whole measuring system.
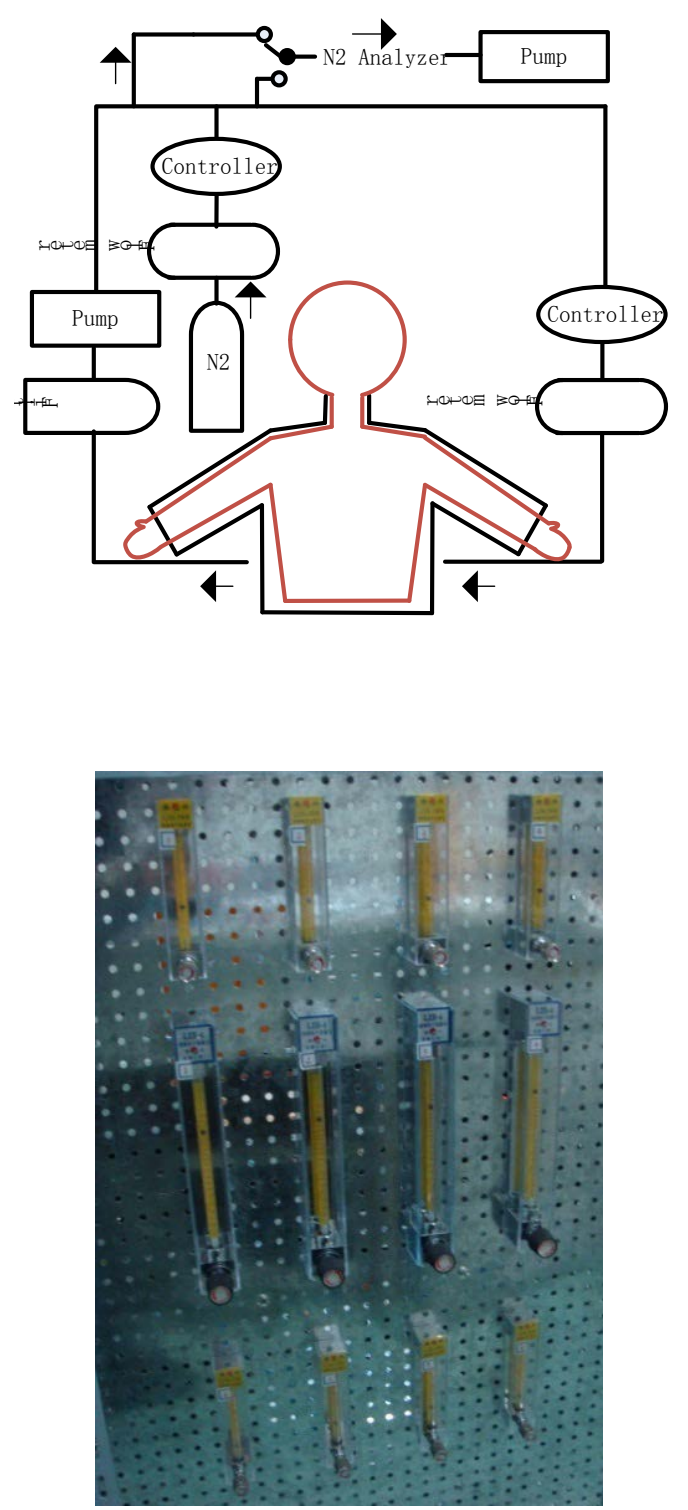

(a)
Fig. 2 Schematic diagram of the local ventilation system for one location

$\mathrm{N}_{2}$ was chosen as the tracer gas. It was pre-mixed with the microclimate air before going into the garment. The flow rate of pure $\mathrm{N}_{2}$ was controlled bellow $0.2 \mathrm{l} / \mathrm{min}$, compared with the main flow rate, about $2.2 \mathrm{l} / \mathrm{min}$. The $\mathrm{N}_{2}$ concentration measuring system was a $\mathrm{N}_{2}$ analyzer (KN-99, China). A 3-way valve was used to change between the inlet and outlet $\mathrm{N}_{2}$ concentrations analyzed by the $\mathrm{N}_{2}$ analyzer.

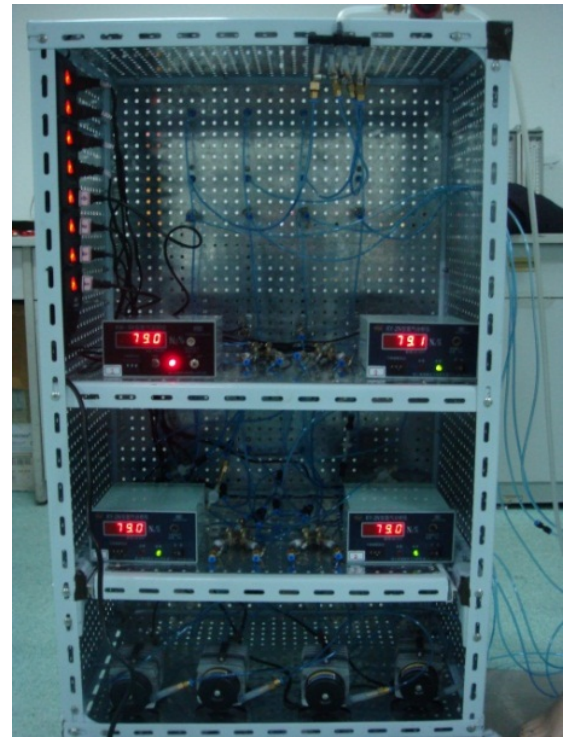

(b) 
Fig. 3 Photograph of the local ventilation rates measuring system. (a) Front view; (b) Back view.

Computation of the whole and local ventila-

tion

For each location, microclimate ventilation rate $\left(\right.$ Vent $\left._{\mathrm{i}}\right)$ is $[4,19]$ :

$$
\text { Vent }_{i}=\mathrm{FR}_{i} \times \frac{C_{\text {in }, i}-C_{\text {out }, i}}{C_{\text {out }, i}-C_{\text {air }, i}}
$$

Where i stands for different garment locations,

from 1 to 4, FR is the flow rate of local circulating system (L/min), $C_{i n}$ is $\mathrm{N}_{2}$ concentration of the inlet flow (\%), $C_{\text {out }}$ is $\mathrm{N}_{2}$ concentration of the outlet flow (\%), $C_{a i r, i}$ is the $\mathrm{N}_{2}$ concentration of the atmosphere around the $\mathrm{i}^{\text {th }}$ clothed body (\%).

In addition, the system can also measure whole ventilation indirectly. That is:

$\overline{\text { Vent }}=\frac{\overline{C_{\text {in }}}-\overline{C_{\text {out }}}}{\overline{C_{\text {out }}}-\overline{C_{\text {air }}}} \sum_{\mathrm{i}=1}^{4}(\text { Circulating flow })_{i}$

$\overline{C_{i n}}=\frac{\sum_{i=1}^{4}\left(C_{i n} \times \text { Circulating flow }\right)_{i}}{\sum_{i=1}^{4}(\text { Circulating flow })_{i}}$

$\overline{C_{\text {out }}}=\frac{\sum_{i=1}^{4}\left(C_{\text {out }} \times \text { Circulating flow }\right)_{i}}{\sum_{i=1}^{4}(\text { Circulating flow })_{i}}$

$\overline{\text { Vent }}$ is the average ventilation of the whole upper garment, $\overline{C_{i n}}$ is the average Argon concentration of the inflow (\%), $\overline{C_{\text {out }}}$ is the average Argon concentration under microclimate (\%), $\overline{C_{\text {air }}}$ is the average Argon concentration of the air around the clothed upper body (\%).

\section{The effect of bottom open conditions}

To study the effect of close or open conditions of the garment bottom on clothing local ventilation, we measured ventilation rates at two bottom conditions: bottom open, bottom closed. As the tracer gas sampling and distribution tubes passed the garment bottom, it was difficult to close the bottom completely.

\section{Wind effect}

To study the effect of head-on wind on clothing local ventilation, a fan system was set about $1.5 \mathrm{~m}$ ahead of the clothed shop manikin. Three wind speeds were used, no wind (air speed < $0.1 \mathrm{~m} / \mathrm{s}), 0.6 \mathrm{~m} / \mathrm{s}$ and $0.9 \mathrm{~m} / \mathrm{s}$.

\section{Experimental design}

The experiment was carried out in an air con- 
ditioned chamber at $20 \pm 2^{\circ} \mathrm{C}, 40 \pm 10 \%$ relative humidity and air flow $<0.1 \mathrm{~m} / \mathrm{s}$. A standing up shop manikin was used to do testing for reducing the impacts of human body shape.

After the circulation pumps were switched on, the pure $\mathrm{N}_{2}$ was pushed into the main flow with the flow rate controlled bellow $0.21 / \mathrm{min}$. Then the $\mathrm{N}_{2}$ concentrations of the inlet and outlet flow of the three parts were monitored by switching on 3-way valves until reaching a steady state. The circulating flow rates of the three separate systems were controlled to almost the same, 2.2 1/min. An $\mathrm{O}_{2}$ analyzer (PGM-1600, USA) was used to monitor the $\mathrm{O}_{2}$ concentration in the chamber. This can tell us the $\mathrm{N}_{2}$ concentration outside the clothed manikin.

6 conditions (two bottom conditions, 3 wind conditions) were tested for each of the nine jackets. At least four times were tested for each specimen. The door of the chamber was opened every two hours to remove the additional $\mathrm{N}_{2}$.

\section{Results and Discussion}

\section{Local VR of the right arm, the chest and the}

back

Fig. 4 shows the local VR of the right arm, the chest and the back for different garments at different wind speeds, clothing sizes and bottom conditions. The 'Group' label means 'wind speed-garment bottom condition’. For example, the '0.6-OPEN' means the measurements were performed at $0.6 \mathrm{~m} / \mathrm{s}$ wind and garment bottom open conditions. The ' $\mathrm{X}$ ' coordinates stands for 'garment size-garment permeability'. For example, 'S1-PM' means the permeable garment of size $\mathrm{S} 1$.

\section{Local VR of the right arm}

For S1 permeable garment, the VR ranges from 7.74 to $26.75 \mathrm{l} / \mathrm{min}$; For $\mathrm{S} 1$ semi-permeable garment, the VR ranges from 8.37 to $28.89 \mathrm{l} / \mathrm{min}$; For S1 impermeable garment, the VR ranges from 1.84 to $2.64 \mathrm{l} / \mathrm{min}$. For S2 permeable garment, the VR ranges from 8.78 
to $21.63 \mathrm{l} / \mathrm{min}$; For $\mathrm{S} 2$ semi-permeable garment, the VR ranges from 10.15 to $32.65 \mathrm{l} / \mathrm{min}$; For S2 impermeable garment, the VR ranges from 1.74 to $4.84 \mathrm{l} / \mathrm{min}$; For S3 permeable garment, the VR ranges from 12.27 to $36.41 \mathrm{l} / \mathrm{min}$; For S3 semi-permeable garment, the VR ranges from 9.89 to $28.29 \mathrm{l} / \mathrm{min}$; For impermeable garment, the VR ranges from 1.96 to $5.32 \mathrm{l} / \mathrm{min}$.

It was obvious that the VR of the S3 permeable garment was largest, and that of the S1 impermeable garment was smallest. The permeable garments had the largest VR, followed by the semi-permeable garments.

Wind increased ventilation at all the conditions. The VR when closing garment bottom were different from those of when bottom open conditions.

\section{Local VR of the chest}

For S1 permeable garment, the VR ranges from 24.22 to $37.20 \mathrm{l} / \mathrm{min}$; For $\mathrm{S} 1$ semi-permeable garment, the VR ranges from 20.03 to 40.76 1/min; For S1 impermeable gar- ment, the VR ranges from 10.90 to $31.13 \mathrm{l} / \mathrm{min}$. For S2 permeable garment, the VR ranges from 19.03 to 58.47 1/min; For S2 semi- permeable garment, the VR ranges from 27.61 to 42.00 1/min; For S2 impermeable garment, the VR ranges from 9.72 to 32.16 1/min; For S3 permeable garment, the VR ranges from 19.03 to39.52 1/min; For S3 semi-permeable garment, the VR ranges from38.25 to 68.00 l/min; For impermeable garment, the VR ranges from 9.69 to 31.54 l/min.

Wind also increased chest ventilation obviously. Chest ventilation rates of impermeable garments were smallest.

\section{Local VR of the back}

For S1 permeable garment, the VR ranges from11.77 to $15.88 \quad \mathrm{l} / \mathrm{min}$; For $\mathrm{S} 1$ semi-permeable garment, the VR ranges from 14.80 to $29.09 \mathrm{l} / \mathrm{min}$; For S1 impermeable garment, the VR ranges from 7.05 to $14.92 \mathrm{l} / \mathrm{min}$. For S2 permeable garment, the VR ranges from 15.53 to 20.39 l/min; For S2 semi-permeable 
garment, the VR ranges from 19.35 to 36.71

1/min; For S2 impermeable garment, the VR ranges from 7.28 to 17.30 l/min; For S3 permeable garment, the VR ranges from 13.64 to 19.97 1/min; For S3 semi-permeable garment, the VR ranges from16.96 to $31.58 \mathrm{l} / \mathrm{min}$; For impermeable garment, the VR ranges from 6.32 to 15.79 $1 / \min$.

For back, the ventilation rates of S2 garments were largest, compared with size S1 and S3.
Wind affected back ventilation obviously. But the situation was very complex. For the same garment size, back VR of semi-permeable garments were largest.

For bottom closing conditions, wind increased ventilation except the S3 impermeable garment. $0.9 \mathrm{~m} / \mathrm{s}$ wind decreased ventilation rates for garment S1-PM, S2-SM, and S3-PM when garment bottom was open.

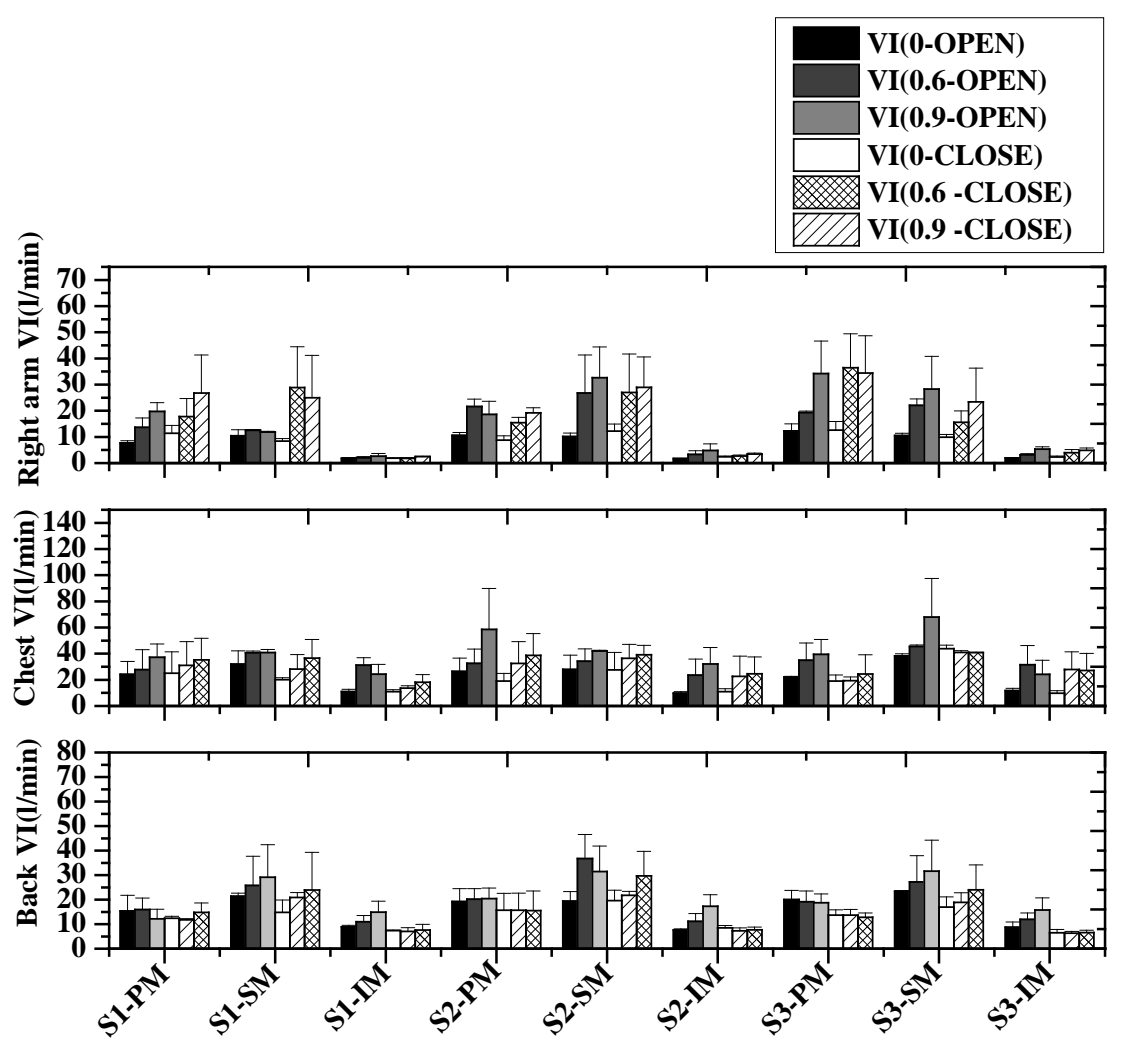

Garment

Fig.4 Clothing local ventilation rates of the right arm, the chest and the back at different conditions. 
The effects of air permeability on clothing

\section{local ventilation}

As shown in Fig. 4, air permeability of garment affected ventilation obviously. The impermeable garments had the smallest VR.

For right arm, the VR of S1 permeable garment were larger than VR of semi-permeable garment except at 0.6-CLOSE conditions. For size S2, the VR of the semi-permeable garment were larger than permeable garment. And for size S3, the VR of permeable garment was larger than semi -permeable garment.

For chest, the VR of semi-permeable garments were larger than permeable garments except for some situations of garment S1. The reason may be that the semi-permeable fabric was stiffer than the permeable fabric. This caused the bigger microclimate volume of semi-permeable garment compared with permeable-garment[19].

For back, the VR of semi-permeable garments were all larger than the permeable garments.
Therefore, the effects of air permeability on local ventilation of different locations were different. Although the permeable garments have more air exchange through fabric, the local ventilation of chest and back were affected more by clothing microclimate conditions.

\section{The effects of clothing sizes on local ventila-}

tion

Different garment sizes had different local VR, as shown in Fig.4.Overall, the smaller of the garment size, the larger of the ventilation rates. This results were similar to that of Havenith et al's [20]. After analyzing the effects of clothing sizes on local VR at each condition one by one, we found that: the local VR differences between garment S2 or S3 and garment S1 were much higher than the local VR differences between garmentsS3 and S2. This was reasonable, as the larger the garment, the better of the garment drapability. And the microclimate difference between garment S2 or S3 and garment S1 was 
much higher than that of the differences between garments S2 and S3.

The effects of bottom open or close condi-

\section{tions on local ventilation}

It can be found that the greater the head-on wind speed, the bigger decrease of VR when closing garment bottom (Fig.4). Because the total VR decreased $10.31 \%$ when closing garment bottom for no wind conditions, $13.11 \%$ for $0.6 \mathrm{~m} / \mathrm{s}$ wind conditions and $16.78 \%$ for $0.9 \mathrm{~m} / \mathrm{s}$ wind conditions.

The effects of bottom open or close conditions on local VR were different according to different locations and fabric permeability. For right arm, the VR increased when closing bottom compared with the VR of bottom open conditions except for impermeable garment at wind conditions. For chest and back, the VR decreased when closing bottom compared with when bottom open for all garments and conditions.

Although the garment bottom closing method in this study changed clothing microclimate, we can still conclude that the air exchanges of chest and back through garment bottom were larger than that of the right arm. And the main air exchange way of clothing right arm was not through garment bottom.

\section{The effects of wind on clothing local ventila-}

tion

It has been proved that wind increased ventilation[19,20]. The effects of wind on clothing local ventilation were also proved in this study, as shown in Fig. 5. The effects of wind on each location were different. $0.6 \mathrm{~m} / \mathrm{s}$ wind increased right arm ventilation on average by $85 \%$, chest VR by $49 \%$, back VR by $24 \%$. $0.9 \mathrm{~m} / \mathrm{s}$ wind increased right arm VR by $136 \%$, chest VR by $81 \%$ and back VR by 33\%.

For right arm, wind increased more air exchange when bottom closing for permeable and semi-permeable garments. The reason may be that the microclimate conditions of the garment were changed when the bottom was closed. Therefore, for arm VR of permeable or 
semi-permeable garment, most of the air exchange is not through garment bottom. For impermeable garment, right arm VR increased when having head-on wind for both bottom close and open conditions. VR decreased on average by about $10 \%$ when closing bottom. For chest, wind increased much more VR for impermeable garment compared with permeable and semi-permeable garment. The head-on wind changed the chest microclimate and forced the air in chest going into other body parts. For back, wind increased VR obviously for semi -permeable garments. For impermeable garment,
VR increased obviously for bottom open conditions. But the back VR decreased when garment bottom was closed. Therefore, for impermeable garment, the main air exchange way for back was through garment bottom.

Overall, the effects of wind on clothing local VR were very much complicated. Wind not only increased the air exchange through fabric, but also changed the microclimate conditions of clothing. But we can still conclude that for impermeable garment, wind increased the air exchange through garment bottom for chest and back.

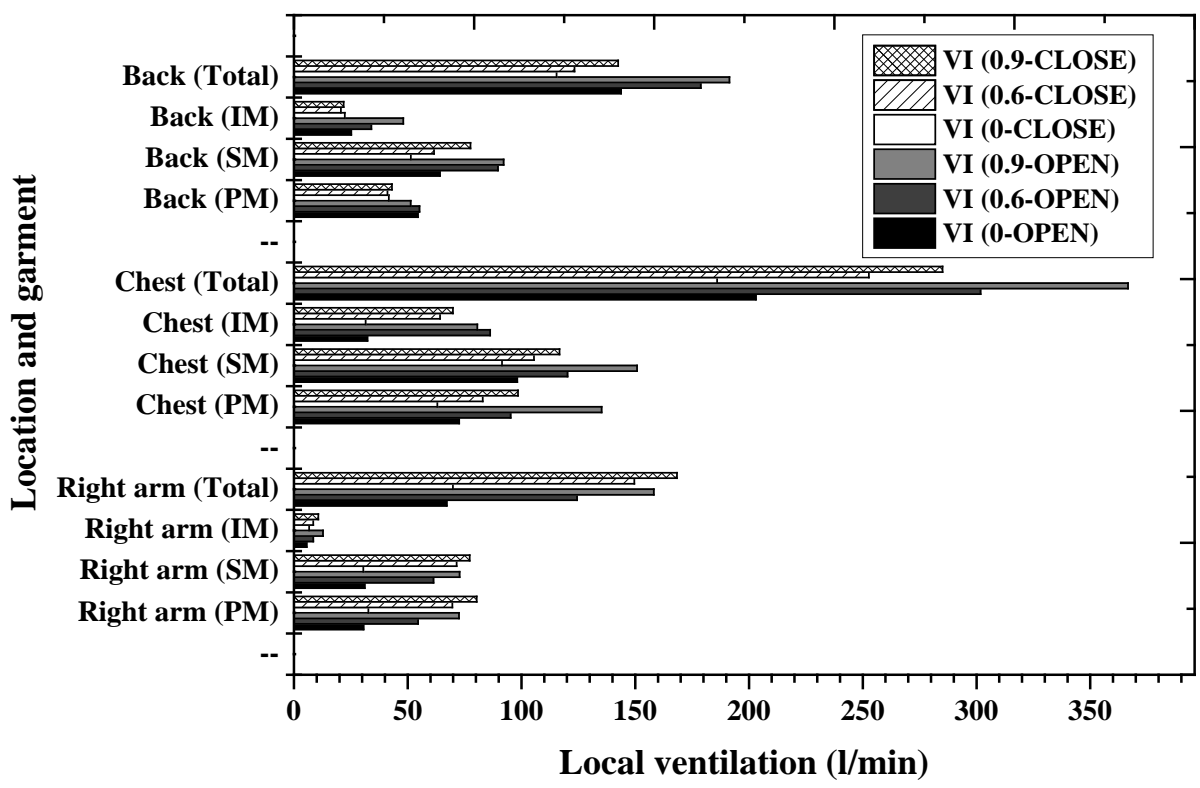

Fig.5 Sum of the local ventilation rates of garments with identical size 
The comparisons between different garment parts

The VR of right arm, chest and back were significantly different from each other. While the conditions between bottom open and closed were different. For bottom open conditions, the chest had the largest VR, followed by back. While for bottom closed conditions, the chest still had the largest VR, but followed by the right arm. Therefore, it can be conclude that for the experimental garment in this study, the back air exchange through garment bottom was larger than the right arm and chest. The chest ventilation contributed most to the whole ventilation.

Whole VR of the experimental jackets at dif-

\section{ferent wind conditions}

Fig.6 shows the whole ventilation of the experimental garments at different conditions. Only the whole VR when the garment bottom was open were computed and compared. The whole VR of S1-PM ranges from 36.57 (This smallest whole VR happened at no wind \&bottom open conditions) to $54.00 \mathrm{l} / \mathrm{min}$ (This largest whole VR happened at $0.9 \mathrm{~m} / \mathrm{s} \&$ bottom closed conditions). The whole VR of S1-SM ranges from 38.23 (no wind \&bottom closed) to 66.55 (0.6 $\mathrm{m} / \mathrm{s}$ wind \& bottom closed) l/min. The whole VR of S1 -IM ranges from 13.13 (no wind \&bottom closed) to 19.37 (0.9 m/s \&bottom open). The whole VR of S2-PM ranges from 38.22 (no wind \&bottom closed) to $71.76 \mathrm{~m} / \mathrm{s}(0.9 \mathrm{~m} / \mathrm{s}$ \&bottom open). The whole VR of S2-SM ranges from 48.30 (no wind \&bottom open) to 96.58 $\mathrm{m} / \mathrm{s}(0.9 \mathrm{~m} / \mathrm{s}$ \&bottom open). The whole VR of S2-IM ranges from 12.78 (no wind \&bottom open) to $29.84 \mathrm{l} / \mathrm{min}(0.9 \mathrm{~m} / \mathrm{s} \&$ bottom open $)$. The whole VR of S3-PM ranges from 27.25(no wind \&bottom closed) to $75.42 \mathrm{l} / \mathrm{min}(0.9 \mathrm{~m} / \mathrm{s}$ \&bottom open). The whole VR of S3-SM ranges from 50.26 (no wind \&bottom closed) to 99.75 1/min ( $0.9 \mathrm{~m} / \mathrm{s}$ \&bottom open). The whole VR of the S3-IM ranges from 13.92 (no wind) to 31.23 
1/min (0.9 m/s \&bottom open).

The impermeable garments always had the smallest whole VR. S1 size garments had the smallest whole VR. The difference between size S1 and S2 or S3 was much higher than that of between size S2 and S3. It was interesting that the semi-permeable garments had the largest whole VR. This may be caused by the properties of the fabrics, which impacted the shape of the garments. Wind increased whole VR significantly both at bottom open and closed conditions.

For whole clothing VR, the effects of fabric permeability, clothing sizes and wind were also obviously. But the situations were different from those of local VR. Thus the results demonstrated that it was necessary to both study the whole VR and local VR.

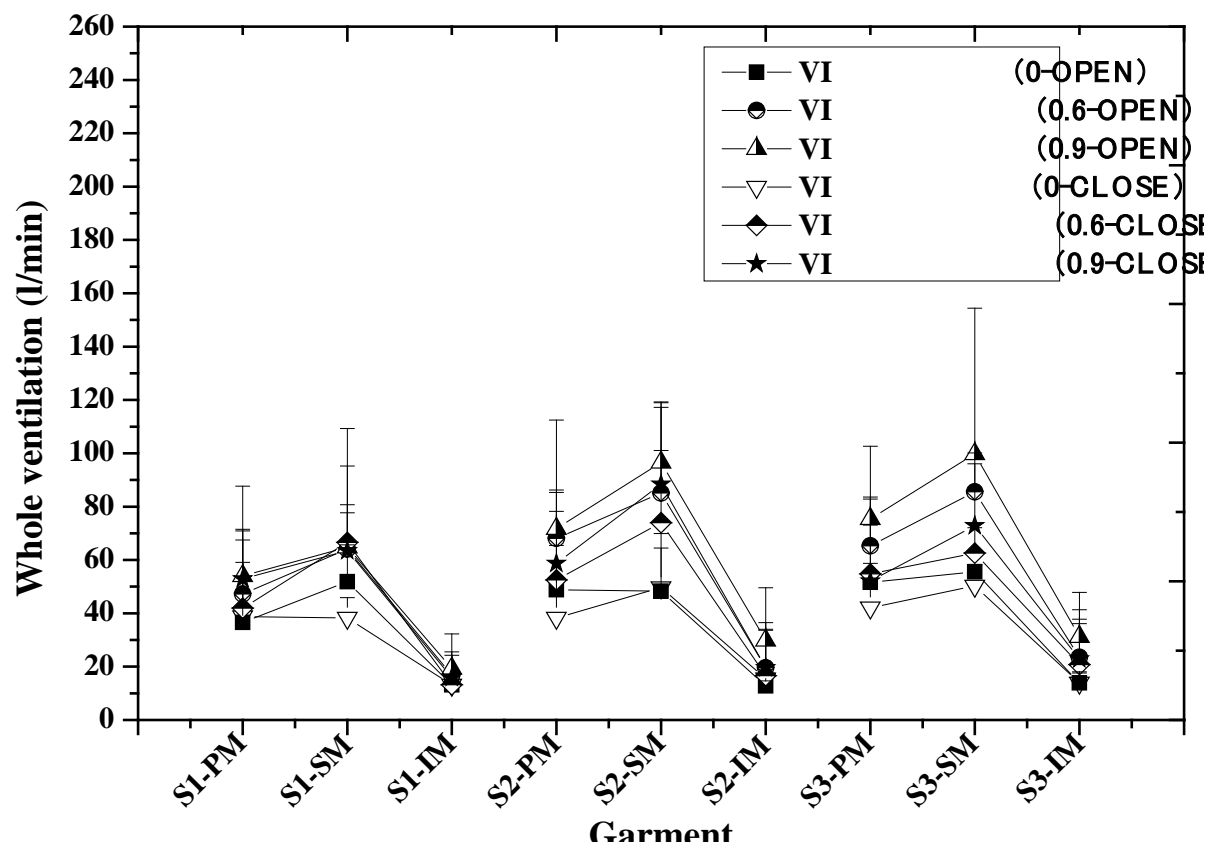

Fig.6 Whole ventilation of different garments at different conditions

\section{Conclusion}

In this paper, a clothing local ventilation sys-

tem was set based on the steady-state method[6, 
20]. This system can measure the right arm, the left arm, the chest and the back ventilation rates at the same time. The system can also measure the whole garment ventilation rates indirectly. To study the influence of the clothing sizes, openings, fabric permeability and wind on local ventilation rates, 9 jackets with different sizes and permeability were made. Both local VR and whole VR were computed and analyzed.

The results showed that the local ventilation rates for different garment locations were different. The impermeable garments had the smallest local and whole VR. It was interesting that the semi-permeable garments had the largest ventilation rates. The main reason was the permeability differences between garments were not big enough. And the fabric properties impacted ventilation rates more comparatively.

Clothing sizes also impacted local and whole VR significantly. But the ventilation rates were not liner with the clothing sizes. As the clothing microclimate was not related to garment size, but also to garment drapability property.

Local VR were also affected by the garment bottom open or close conditions. The influence of bottom close on local VR was more obvious for chest and back comparatively. It can demonstrate that there is more air exchange through garment bottom for chest and back.

Wind increased local VR of all the three locations obviously. Wind increased the right arm ventilation most. This may be related to the experimental garment structure. Because the sleeve had a vent on it, the wind increased more air exchange between the sleeve and outside air through the vent.

This study indicates that the fabric permeability, clothing sizes, bottom opening conditions and wind affect both clothing whole and local VR obviously. And these factors interact with each other. This study also indicates that when evaluating work wear, it is necessary to measure both clothing whole and local ventilation. And it is also necessary to measure clothing ventilation 
at different conditions.

We thank the staff of Environmental Ergonomics Research Center of Loughborough University for their help to this study. We give thanks to the part financial support of the National Natural Science Foundation (51106022), Innovation Program of Shanghai Municipal Education Commission (12ZZ068, Shanghai Pujiang Program), and National Social Science Foundation (12DG36).

\section{References}

1. R.R. Brinbaum, G.W. Crockford, Appl. Ergon, 9, 194 (1978).

2. G. Havenith, Ann. Occup. Hyg. , 43, 289 (1999).

3. G. Havenith, Exoge. Derma. , 1, 221 (2002).

4. G. Havenith, P. Zhang, K. Hatcher, H. Daanen, Ergon. , 53, 548 (2010).

5. G. W. Crockford, M. Crowder M, S.P. Pres- tidg, Brit. J. Ind. Med. , 29, 378 (1972).

6. W. A. Lotens, G. Havenith, Envir. Ergon. , 34, 162 (1988)

7. G. Havenith, U. Hiroyuki, S. Hayet, I. Yoshimitsu , Proc. 2nd Euro. Conf. Prot. Cloth., Switzerland, 21 (2003).

8. H. Ueda, G. Havenith, Envir. Ergon, 343

(2005).

9. H. Ueda, Y. Inoue, G. Havenith, 11th Inter. Conf. Envir. Ergon. , Sweden, 411 (2005)

10. H. Ueda, Y. Inoue, M. Matsudaira, T. Araki, G. Havenith, Inter. J. Cloth. Sci. and Tech. , 18, 225 (2006).

11. Y. Satsumoto, G. Havenith, Tex. Res. J. , 80 , 1859 (2010).

12. J. Cotter, M. Patterson, n. Taylor, Eur. J. App. Physiol. Occup. Physiol. , 71, 549 (1995).

13. G. Havenith G, A. Fogarty, R. Bartlett, C. Smith, V. Ventenat, Euro. J. Appl. Physiol. , 104, 245 (2008).

14. C. Smith, G. Havenith, Euro. J. Appl. Physiol. , 111, 1391 (2011). 
15. C. Smith, G. Havenith, Med. Sci. Sports Ex-

ercise, 44, 2350 (2012).

16. N. Taylor, F. Caldwell, I. Mekjavic, Avia.

Space Envir. Med. , 77, 1020 (2006).

17. S.H. Lumley, D.L. Story, N.T. Thomas, Appl.

Ergon., 22, 390 (1991).
18. W. A. Lotens, G. Havenith , Ergon. , 34, 233

(1991).

19. G. Havenith, R. Heus, W. A. Lotens, Ergon. , 33, 67 (1990).

20. G.Havenith, R. Heus, W. A. Lotens, Ergon.

33, 989 (1990). 